Western University

Scholarship@Western

Department of Economics Research Reports

Economics Working Papers Archive

1990

\title{
Habit Persistence and the Harberger-Laursen- Metzler Effect in an Infinite Horizon Model
}

Arman Mansoorian

Follow this and additional works at: https://ir.lib.uwo.ca/economicsresrpt

Part of the Economics Commons

Citation of this paper:

Mansoorian, Arman. "Habit Persistence and the Harberger-Laursen-Metzler Effect in an Infinite Horizon Model." Department of Economics Research Reports, 9011. London, ON: Department of Economics, University of Western Ontario (1990). 
RESEARCH REPORT 9011

HABIT PERSISTENCE AND THE

HARBERGER-LAURSEN-METZLER EFFECT IN

AN INFINTIE HORIZON MODEL

by

Arman Mansoorian

September 1990

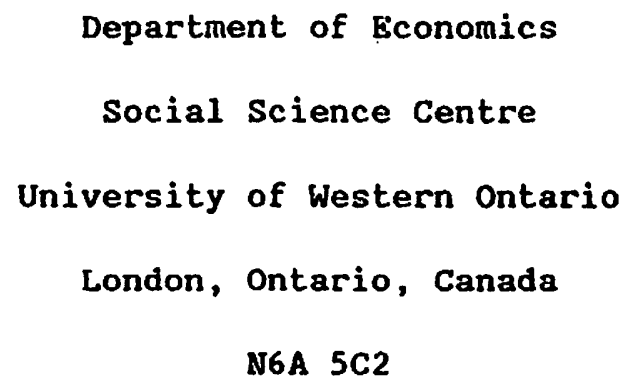

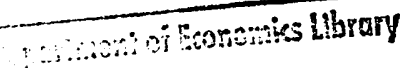

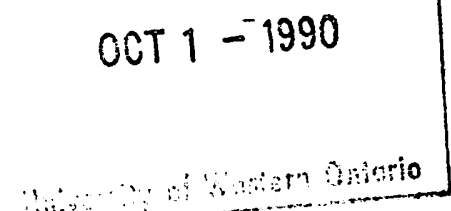


HABIT PERSISTENCE AND

THE HARBERGER-LAURSEN-METZLER EFFECT

IN AN INFINITE HORIZON MODEL

by

Arman Mansoorian

Department of Economics

Social Science Centre

University of Western Ontario

London, Ontario, Canada

N6A 5C2

\begin{abstract}
The habit persistence model of Ryder and Heal is used to examine the HarbergerLaursen-Metzler (H-L-M) effect. The model captures Keynes's "fundamental psychological law", which underlied the original intuition for the H-L-M effect. Our results are in contrast to the general view in the literature that the stability requirements preclude the H-L-M effect in an infinite horizon model. We show that if the habitual standard of living adjusts fast enough to changes in real consumption then the H-L-M effect holds, and a terms of trade deterioration reduces savings. However, if the habitual standard of living adjusts slowly to changes in real consumption, then the stability requirements dominate the intuition for the H-L-M effect, and the opposite result is obtained.
\end{abstract}

$J E L$ classifications: 431,433 


\section{Introduction}

The original intuition for the Haberger-Laursen-Metzler (H-L-M) effect was based on Keynes's (1936) "fundamental psychological law", according to which "a man's habitual standard of life usually has the first claim on his income, and he is apt to save the difference which discovers itself between his actual income and the expense of his habitual standard" (p. 97). Thus, a terms of trade deterioration, which reduces the permanent real income of the country, leads to a fall in savings and a current account deficit, because agents try to maintain their habitual standards of living.

Neither Harberger (1950), nor Laursen and Metzler (1950) based their study on an explicit optimizing framework. Obstfeld (1982) was the first to use an optimizing framework to determine the effect of a terms of trade deterioration on savings and the current account. He uses an infinite horizon exchange economy where the representative agent has Uzawa's (1968) utility function. In that framework, he finds that, contrary to the H-L-M effect, a terms of trade deterioration leads to an increase in savings and a current account surplus.

The reason for Obstfeld's result is that with Uzawa's utility function the rate of time preference (RTP) is increasing in instantaneous utility. In the steady state this RTP must be equal to the world rate of interest, which gives a unique level of instantaneous utility that must be maintained in a steady state. After a terms of trade deterioration the only way this steady state level of utility can be re-established is if aggregate expenditure in the steady state rises. This requires the country to run a current account surplus, and accumulate assets along the adjustment path to the new steady state.

Svensson and Razin (1983) show that the main reason for Obstfeld's result is that for the stability of the steady state equilibrium he has to assume that the RTP is increasing in instantaneous utility. This has led to the general view in the literature that the stability requirements prevent the $\mathrm{H}-\mathrm{L}-\mathrm{M}$ effect in an infinite horizon model. 
Note that with Uzawa's utility function momentary utility is independent of history; it depends only on current consumption, which jumps in order to accommodate the steady state level of standard of living. Thus, Obstfeld's model does not capture the original intuition for the H-L-M effect in any way, and its dynamics are dominated by the stability requirements. It; moreover, has the counterfactual prediction that consumption is not smooth, but it jumps in response to any exogenous shock.

Persson and Svensson (1985) argue that the assumption that the RTP is increasing in instantaneous utility is "arbitrary and even counterintuitive" (p. 45). ${ }^{1}$ However, instead of using a utility function that captures the original intuition for the H-L-M effect, they abandon the infinite horizon framework. In in its place, they use an overlapping generation (OLG) framework, because, they argue, the OLG framework has "nice stability properties, without arbitrary restrictions on the rate of time preference" (p. 45). In the two period OLG framework that they employ, aggregate savings is given by the savings of the young, because the old spend all their income. As the young supply the country's labour, while the old hold the non-human factors, the effect of an unanticipated permanent terms of trade deterioration on aggregate savings depends primarily on what happens to the wage rate. Matsuyama (1988) shows that, in this framework, if both goods are produced then the effect of a terms of trade deterioration on aggregate savings and the current account will depend on the relative factor intensities of the goods in production. ${ }^{2}$ Although this is an interesting result on its own, it is specific to the OLG framework. It is, furthermore, very different from the original intuition for the H-L-M effect.

1However, see Epstein and Hynes (1983) for a thorough study of the main advantages of Uzawa type utility functions.

${ }^{2}$ Also see Matsuyama (1987). Sen and Turnovsky (1989), on the other hand, use an infinite horizon model with a fixed RTP, but allow for labour-leisure choice and for capital accumulation. In their model the effect of a terms of trade deterioration on the current account is ambiguous; it depends on the behaviour of investment, which is different from the intuition for the H-L-M effect. The latter pertains to the partial derivative of the savings function with respect to the real exchange rate. 
In this paper we retain the infinite horizon exchange economy of Obstfeld, but we use the habit persistence utility function of Ryder and Heal (1973). This utility function captures the original intuition underlying the H-L-M effect. It has recently been used by Becker and Murphy (1988) in constructing a theory of rational addiction, and by Constantinides (1990) in providing a resolution for the equity premium puzzle. Unlike Obstfeld's model, in the present model the RTP is fixed. Moreover, momentary utility depends not only on current real consumption, but also on the habitual standard of living, which is a weighted average of past levvels of real consumption. This specification captures Keynes's "fundamental psychological law": agents try to maintain their habitual standards of living after an exogenous shock.

In our framework the H-L-M effect can hold, but is not inevitable. A terms of trade deterioration reduces the permanent real income of the country, necessitating a fall in its steady state habitual standard of living. If the habitual standard of living adjusts fast to changes in real consumption, then this required fall in its steady state level can be achieved smoothly, and the stability requirements do not dominate the intuition for the H-L-M effect. In this case, after a terms of trade deterioration savings fall because the representative agent tries to maintain his habitual standard of living. Thus, the country runs a current account deficit, and then real consumption falls smoothly to its long run level.

If, on the other hand, the habitual standard of living adjusts slowly to changes in real consumption, then the stability requirements override the intuition for the H-L-M effect. In this case, the only way the long run habitual standard of living can fall by a sufficiently large amount to accommodate the fall in the country's permanent real income is if real consumption falls by a very large amount in the short run. Therefore, after the terms of trade deterioration, savings rise and the country runs a current account surplus. As in Obstfeld's model, this result comes about because of the stability requirements.

The paper is organised as follows. The model is presented in section II. The effects of a terms of trade deterioration are discussed in section III. Some concluding remarks are made in section IV. 


\section{The Model}

The objective function of the representative agent is a two good variant of that used by Ryder and Heal:

$$
\int_{0}^{\infty} e^{-\delta t} U\left(\omega\left(c_{t}^{f}, c_{l}^{h}\right), S_{r}\right),
$$

where $\omega(\cdot)$ is a homothetic subutility function, $c_{t}^{f}$ and $c_{i}^{h}$ are consumptions of the foreign and home goods at time $t, S_{t}$ is the expected (or habitual) standard of living at time $t$, and $\delta$ is the (fixed) rate of time preference. Note that $\omega\left(c_{t}^{f}, c_{t}^{h}\right)$ gives a measure of the consumption of the two goods in utility terms. Henceforth, we will refer to it as real consumption at time $t$.

Therefore, according to (1), the momentary utility function $U(\cdot)$ depends not only on current real consumption but also on the habitual standard of living inherited from the past.

As in Ryder and Heal, we make the following five assumptions about the momentary utility function:

(A.1) $\quad U_{\omega}(\omega, S)>0$. Thus, instantaneous utility is increasing in real consumption.

(A.2) $U_{S}(\omega, S) \leq 0$. Thus, instantaneous utility is non-increasing in the habitual standard of living.

(A.3) $U_{\omega}(\omega, \omega)+U_{S}(\omega, \omega)>0$. Thus, an increase in $\omega$ that is uniformly maintained will increase utility. ${ }^{3}$

(A.4) $\quad U_{\omega \omega}(\omega, S)<0, U_{S S}(\omega, S)<0, U_{\omega \omega}(\omega, S) U_{s S}(\omega, S)-\left[U_{\omega s}(\omega, S)\right]^{2} \geq 0$. Thus, the momentary utility function is concave in $\omega$ and $S$.

(A.5) $\quad \lim _{\omega \rightarrow 0} U_{\omega}(\omega, S)=\infty$ uniformly in $S$; and $\underset{\omega \rightarrow 0}{\operatorname{Lim}}\left[U_{\omega}(\omega, \omega)+U_{S}(\omega, \omega)\right]=\infty$.

${ }^{3}$ Ryder and Heal show that the relaxation of this assumption leads to multiple satiated stationary equilibria. Such equilibria do not throw additional light on the issue under consideration. We maintain the assumption to be consistent with the international finance literature. 
The determination of the habitual standard of living is also the same as in Ryder and Heal. We assume that $S_{t}$ is a weighted average of $\omega\left(c_{\tau}^{f} c_{\tau}^{h}\right)(\tau<t)$, with exponentially declining weights being given to more distant values of $\omega\left(c_{\tau}^{f} c_{\tau}^{h}\right)$. Thus,

$$
S_{t}=\rho e^{-\rho t} \int_{-\infty}^{t} e^{\rho \tau} \omega\left(c_{\tau}^{f} c_{\tau}^{h}\right) d \tau
$$

where $\rho>0$. A larger $\rho$ means smaller weights will be given to more distant values of $\omega$.

(2) then implies that the evolution of $S_{t}$ is given by

$$
\dot{S}_{t}=\rho\left(\omega\left(c_{t}^{f}, c_{t}^{h}\right)-S_{l}\right)
$$

As in Obstfeld, at any point in time the country is endowed with $y$ units of the home good and nothing of the foreign good. The home good is taken to be the numeraire, while the price of the foreign good is fixed abroad at $p$. The world rate of interest is also fixed abroad at $r$. Thus, the country's intertemporal budget constraint at time $t$ is

$$
\dot{B}_{t}=r B_{t}+y-Z_{t}
$$

where $Z_{t}$ is aggregate expenditure at time $t\left(c_{t}^{h}+p c_{t}^{f}\right)$, and $B_{t}$ is the country's net foreign asset position at time $t$.

In what follows, it is important to keep a clear distinction between aggregate expenditure $(Z)$ and real consumption $(\omega)$. The former is the value of goods consumed, while the latter is a utility measure of the goods consumed.

To prevent the country from borrowing without bound, we require that at any point in time the present value of its output should not exceed its net indebtedness. That is,

$$
A_{t} \equiv \frac{y}{r}+B_{t} \geq 0, \forall t
$$

We assume that at time $O$ the country starts with $B_{0}$ and $S_{0}$ values of $B$ and $S$, respectively.

The problem of the representative agent is to choose a sequence of consumption levels $\left(c_{t}^{f}, c_{t}^{h}\right)$ to maximize his utility subject to the constraints (3), (4), (5), and the initial levels of $B$ and $S$. 
Even though the agent's preferences are not strongly separable, the marginal rate of substitution between the home and foreign goods at any point in time is independent of the consumption levels at other points in time. Thus, as $\omega(\cdot)$ is homothetic, the agent's maximization problem can be done in two stages. In the first stage, for a given level of expenditure, $Z_{t}$, at any point in time the agent chooses $c_{t}^{f}$ and $c_{t}^{h}$ to maximize $\omega\left(c_{t}^{f}, c_{t}^{h}\right)$ subject to $Z_{t}=c_{t}^{h}+p c_{i}^{f}$. In the second stage the agent chooses the values of $Z_{i}$

The first stage of the agent's problem gives the indirect utility function $Z_{t} V(p)$, where $V^{\prime}<0$. The second stage of his problem then is

$$
\max _{\left\{Z_{t}\right\}} \int_{0}^{\infty} e^{-\delta t} U\left(Z_{t} V(p), S\right) d t
$$

subject to (3), (4), (5), and the initial levels of $B$ and $S$.

The Hamiltonian for this problem is 4

$$
H\left(Z_{t}, S_{t}, B_{t}, \lambda_{t}, \mu_{t}\right)=U\left(Z_{t} V(p), S_{t}\right)+\lambda_{t}\left[\rho\left(Z_{t} V(p)-S_{t}\right)\right]+\mu_{t}\left[r B_{t}+y-Z_{t}\right],
$$

where $\lambda_{t}$ and $\mu_{t}$ are the shadow prices of $S_{t}$ and $B_{t}$ respectively.

For optimality we need:

$$
\begin{aligned}
& H_{Z} \equiv U_{\omega} V+\lambda \rho V-\mu=0, \\
& -H_{S}+\delta \lambda \equiv-U_{S}+\lambda \rho+\delta \lambda=\dot{\lambda}, \\
& -H_{B}+\delta \mu \equiv-r \mu+\delta \mu=\dot{\mu},
\end{aligned}
$$

and the transversality conditions:

$$
\begin{aligned}
& \operatorname{Lim}_{t \rightarrow \infty} e^{-\delta t} \lambda S_{t}=0, \text { and } \\
& \operatorname{Lim}_{t \rightarrow \infty} e^{-\delta} \mu_{t} A_{t}=0 .
\end{aligned}
$$

${ }^{4} S$ trictly, this Hamiltonian should be in terms of $A_{t}$, not $B_{i}$. This is because, for the transversality conditions to be sufficient for optimality, the state variables should always be non-negative (see Arrow and Kurz, p. 49). (5) gives such non-negativity condition for $A_{t}$, while there is none for $B_{i}$. Nevertheless, we choose $B_{t}$ in the optimization process, because from the definition of $A_{t}$ it is clear that choosing $A_{t}$ is equivalent to choosing $B_{i}$. However, the transversality condition (10) is in terms of $A_{t}$, as it should be. 
Given our assumptions (A.1) to (A.5), these conditions characterize an optimal interior solution.

From (8) it is clear that a steady state can be reached only if

$$
\delta=r \text {. }
$$

This is a standard assumption that is made in the literature, and we maintain it from now on. 5 (11) then means that $\dot{\mu}=0$, and that $\mu$ is always at its steady state level.

Linearizing (6) around the steady state, using the fact that $\dot{\mu}=0$, we get

$$
\left(Z_{t}-\bar{Z}\right)=\frac{-U \omega S}{U_{\omega \omega} V}\left(S_{t}-\bar{S}\right)-\frac{\rho}{U_{\omega \omega} V}\left(\lambda_{t}-\bar{\lambda}\right),
$$

where bars over variables denote steady state values.

The dynamics of the model are recursive. The dynamics of $S$ and $\lambda$ are independent of $B$. This makes the analyses straightforward.

Linearizing (7) and (8) around the steady state and using (12), we get

$$
\left[\begin{array}{c}
\dot{S}_{t} \\
\dot{\lambda}_{t}
\end{array}\right]=\left[\begin{array}{ll}
a_{11} & a_{12} \\
a_{21} & a_{22}
\end{array}\right]\left[\begin{array}{l}
S_{t}-\bar{S} \\
\lambda_{t}-\bar{\lambda}
\end{array}\right]
$$

where

$$
\begin{aligned}
& a_{11}=\frac{-\rho\left(U_{\omega S}+U_{\omega \omega}\right)}{U_{\omega \omega}} \\
& a_{12}=\frac{-\rho^{2}}{U_{\omega \omega}}>0, \text { by assumption (A.4) } \\
& a_{21}=\frac{U_{S \omega}-U_{S S} U_{\omega \omega}}{U_{\omega \omega}}>0, \text { by assumption (A.4) }
\end{aligned}
$$

and

$$
a_{22}=r+\frac{\rho\left(U_{\omega \omega}+U_{S \omega}\right)}{U_{\omega \omega}} .
$$

5In contrast, in Obstfeld's model $\delta$ is a function of instantaneous utility, and in that case condition (11) holds only in the steady state. The dynamics of his model are driven by $\delta$. The dynamics of our model, on the other hand, are driven by $S$. 
$S$ is a state variable, while $\lambda$ is a jump variable. Therefore, for saddlepoint stability of the system in (13) we need the determinant of the coefficient matrix to be negative, which, given our assumptions (A.1) to (A.4), can be easily satisfied. If $\theta$ is the negative eigenvalue of this coefficient matrix, then the stable path to the steady state is:

$$
\begin{aligned}
& \left(S_{t}-\bar{S}\right)=\left(S_{0}-\bar{S}\right) e^{\theta}, \\
& \left(\lambda_{t}-\bar{\lambda}\right)=\left(S_{0}-\bar{S}\right) \frac{\theta-a_{11}}{a_{12}} e^{\theta_{t}} .
\end{aligned}
$$

To obtain the solution for $B$, first linearize equation (4), and then use (12), (14) and (15) to get

$$
\dot{B}_{t}=r\left(B_{t}-\bar{B}\right)+\Omega\left(S_{0}-\bar{S}\right) e^{\theta t},
$$

where

$$
\begin{aligned}
\Omega & =\frac{U_{\omega S}}{U_{\omega \omega} V}+\frac{\rho}{U \omega \omega} \frac{\theta-a_{11}}{a_{12}} \\
& =\frac{-\left(1+\frac{\theta}{\rho}\right)}{V} .
\end{aligned}
$$

The solution to (16) is

$$
B_{t}-\bar{B}=\frac{\Omega}{\theta-r}\left(S_{0}-\bar{S}\right) e^{\theta t}+\left[\left(B_{0}-\bar{B}\right)-\frac{\Omega}{\theta-r}\left(S_{0}-\bar{S}\right)\right] e^{r t} \text {. }
$$

Therefore, in order for $B$ to converge to its steady state level, $\vec{B}$, we need

$$
\left(B_{0}-\bar{B}\right)-\frac{\Omega}{\theta-r}\left(S_{0}-\bar{S}\right)=0 \text {. }
$$

Thus, from (17), the solution for $B_{t}$ that is consistent with a saddlepoint steady state equilibrium is 6

$$
B_{t}-\bar{B}=\frac{\Omega}{\theta-r}\left(S_{0}-\bar{S}\right) e^{\theta t}
$$

6Note that, as in a saddlepoint equilibrium all variables assume finite values, the transversality conditions (9) and (10) are satisfied. 


\section{The Effects of a Terms of Trade Deterioration}

In this section we consider the effects of a permanent unanticipated rise in the price of the import good at time 0 . Although the model has two state variables ( $S$ and $B$ ), from (14), (15) and (18) it is clear that the stable path to the steady state equilibrium is monotonic. This makes the analyses very straightforward.

First we consider the effect of an increase in $p$ on the steady state equilibrium. The steady state is characterized by equation (6), and by equations (3), (4) and (7) with $\dot{S}=\dot{B}=\dot{\lambda}=$ 0 . These, however, are four equations in five unknowns: $\bar{Z}, \bar{B}, \bar{S}, \bar{\lambda}$, and $\mu$. The fifth equation is obtained from (18):

$$
B_{0}-\bar{B}=\frac{\Omega}{\theta-r}\left(S_{0}-\bar{S}\right) \text {. }
$$

This gives a relationship between the changes in the steady state levels of $B$ and $S$ :

$$
d \vec{B}=\frac{\Omega}{\theta-r} d \vec{S} .
$$

To obtain the effect of an increase in $p$ on $\bar{S}, \bar{Z}$, and $\bar{B}$, totally differentiate equations

(3), (4), (6) and (7) at the steady state, and use (19) to get:

$$
\begin{aligned}
& \frac{d \bar{S}}{d \bar{p}}=\frac{\bar{Z} V^{\prime}}{1-\frac{\Omega}{\theta-r} V r}<0, \\
& \frac{d \bar{Z}}{d p}=\frac{\left[\frac{r \Omega}{\theta-r}\right] \bar{Z} V^{\prime}}{1-\frac{\Omega}{\theta-r} V r} \gtreqless 0, \text { as } \rho \leqq-\theta,
\end{aligned}
$$

and

$$
\frac{d \vec{B}}{d p}=\frac{\left[\frac{\Omega}{\theta-r}\right] \bar{Z} V^{\prime}}{1-\frac{\Omega}{\theta-r} V r} \gtreqless 0, \text { as } \rho \lesseqgtr-\theta \text {. }
$$

Thus, a terms of trade deterioration leads unambiguously to a fall in the habitual standard of living in the steady state. This is because a rise in $p$ represents a fall in the country's permanent real income. 
From (21) and (22) it is clear that the effect of an increase in $p$ on aggregate expenditure and on the country's net foreign asset position in the steady state depends on the value of $\rho$ relative to $-\theta$. To give the intuition for these results first note that, from (14), $-\theta(>0)$ is the rate at which the representative agent should close the gap between current habitual standard of living and its steady state level along the stable path. Moreover, (14) implies that at time 0

$$
\dot{S}_{0}=-\theta\left(\bar{S}-S_{0}\right)
$$

Now, from (3), $\rho$ is the rate at which the agent closes the gap between real consumption and the habitual standard of living, by changing the latter; and, moreover,

$$
\dot{S}_{0}=\rho\left(\omega_{0}-S_{0}\right) \text {. }
$$

(23) and (24) then imply that

$$
\frac{-\theta}{\rho}=\frac{\omega_{0}-S_{0}}{\bar{S}-S_{0}} \text {. }
$$

(25) must hold at time 0 , right after the rise in $p$. Now, $\bar{S}<S_{0}$ by (20), assuming that we start from a steady state equilibrium before the rise in $p$. Thus, $\omega_{0}<S_{0}$, because $\frac{-\theta}{\rho}>0$. Therefore, after the rise in $p$ real consumption falls.

After the rise in $p, S_{0}$ is predetermined, $\bar{S}$ is given by the parameters of the model, $\rho$ is given by preferences, and $\theta$ is given by the stability conditions. Thus, $\omega_{0}$ jumps to maintain (25). This underlies the intuition for the results in (21) and (22).

First consider the case in which $\rho>-\theta$. In this case the habitual standard of living adjusts relatively fast to changes in real consumption in order for the stability requirements not to dominate the original intuition for the H-L-M effect. After the rise in $p$ the steady state habitual standard of living falls. But, as is clear from (25), when $\rho>-\theta$ real consumption at time 0 does not fall by as much. The reason for this is that at time zero the representative agent has a habitual standard of living $\left(S_{0}\right)$ that he tries to maintain. Therefore, in face of a terms of trade deterioration, and a fall in the country's real permanent income, savings fall, 
causing a current account deficit. Then, real consumption adjusts smoothly to its steady state level. In the new steady state both aggregate expenditure and the country's net foreign asset position are below their levels before the price change, because along the adjustment path the country decumulates assets. Thus, in this case, the response of savings and the current account to a terms of trade deterioration, and the mechanism by which they come about, are analogous to the original intuition for the H-L-M effect. This then is a confirmation of that intuition in an explicit optimizing framework.

Now consider the case in which $\rho<-\theta$. In this case, the habitual standard of living adjusts relatively slowly to changes in real consumption, and the stability requirements override the original intuition for the H-L-M effect. From (25) it is clear that in this case real consumptions at time 0 falls below its steady state level, $\bar{S}$. As habits adjust slowly, the only way a fall in the country's permanent income could be accommodated in the steady state is if after the rise in $p$ real consumption overshoots its long run equilibrium level $(\bar{S})$. Therefore, in this case, after a terms of trade deterioration there is a fall in aggregate expenditure $(Z)$ and a current account improvement. The country accumulates assets, and $Z$ rises along the adjustment path to the long run equilibrium. The initial rise in savings is necessary in this case for stability, which is analogous to the driving force behind Obstfeld's result.

In Obstfeld's model the country does not inherit any habitual standard of living from previous periods. However, there is a unique target level of standard of living for the steady state, which is determined by the equality of the rate of time preference and the world rate of interest. After a terms of trade deterioration, the only way this target level of standard of living can be achieved is if aggregate expenditure in the steady state rises. This requires the country to run a current account surplus along the adjustment path. The mechanism behind Obstfeld's result, therefore, is different from Keynes's "fundamental psychological law"; and it is dominated by the requirements for a stable steady state equilibrium, which is why it is viewed as counterintuitive by some. 


\section{Conclusions}

Following Obstfeld's result, the general view in the literature is that the requirements for a stable steady state equilibrium preclude the H-L-M effect in an infinite horizon exchange economy.

In this paper we have employed the habit persistence model of Ryder and Heal to determine the effect of a terms of trade deterioration on the current account of a small open economy. The habit persistence model captures Keynes's "fundamental psychological law", which underlied the original intuition for the H-L-M effect, according to which a terms of trade deterioration will lead to a reduction in savings and a current account deficit because agents try to maintain their habitual standards of living.

Our conclusion was that if the habitual standard of living adjusts fast enough to changes in real consumption, then the stability requirements will not dominate the original intuition for the H-L-M effect; and the H-L-M effect will hold in an infinite horizon exchange economy. To that extent, our result provides a formal proof of that intuition. Nevertheless, we also showed that if the habitual standard of living does not adjust fast enough to changes in real consumption, then the stability requirements will override the intuition for the H-L-M effect. In that case, in order to accommodate a fall in the country's real income, after a terms of trade deterioration the country should undergo a large fall in its real consumption in the short run, and run a current account surplus.

Finally, note that Uzawa's utility function is very popular compared with the habit persistence model. Our results, however, point out a case in which the latter gives much richer results. 


\section{REFERENCES}

Arrow, K.J., and M. Kurz (1970): Public Investment, the Rate of Return, and Optimal Fiscal Policy (Baltimore: The Johns Hopkins Press).

Becker, Gary S., and Murphy, Kevin M. (1988): "A Theory of Rational Addiction". Journal of Political Economy, 96, No. 4 (August): 675-700.

Constantinides, George M. (1990): "Habit Formation: A Resolution of the Equity Premium Puzzle". Journal of Political Economy, 98, No. 3: 519-543.

Epstein, L. G., and Hynes, J. A. (1983): "The Rate of Time Preference and Dynamic Economic Analysis". Journal of Political Economy, 91, No. 4: 661-635.

Harberger, A. (1950): "Currency Depreciation, Income, and the Balance of Trade". Journal of Political Economy, 58: 47-56.

Keynes, J. M. (1936): The General Theory of Employment, Interest and Money (London: Macmillan).

Laursen, S. and Metzler, L. A. (1950): "Flexible Exchange Rates and the Theory of Employment", Review of Economics and Statistics, 32: 281-299.

Matsuyama, K. (1987): "Current Account Dynamics in a Finite Horizon Model," Journal of International Economics, 23: 299-313.

Matsuyama, K. (1988): "Terms of Trade, Factor Intensities and the Current Account in a Life-Cycle Model", Review of Economic Studies, 55: 247-262.

Obstfeld, M. (1982): "Aggregate Spending and the Terms of Trade: Is There a Laursen-Metzler Effect", Quarterly Journal of Economics, 97: 251-270.

Persson, T. and L. E. O. Svensson (1985): "Current Account Dynamics and the Terms of Trade: Harberger-Laursen-Metzler Two Generations Later", Journal of Political Economy, 93: 43-65.

Ryder, Harl E., and Heál, G. M. (1973): "Optimal Growth with Intertemporally Dependent Preferences", Review of Economic Studies, 40: 1-31. 
Sen, Partha, and Turnovsky, S. J. (1989): "Deterioration of the Terms of Trade and Capitnl Accumulation: A Re-examination of the Laursen-Metzler Effect", Journal of International Economics, 26: 227-250.

Svensson, L. E. O., and Razin, A. (1983): "The Terms of Trade and the Current Account: The Harberger-Laursen-Metzler Effect", Journal of Political Economy, 91: 97-125.

Uzawa, H. (1968): "Time Preference, the Consumption Function, and Optimal Asset Holdings" in J. N. Wolfe (ed.), Value, Capital and Growth: Papers in Honour of Sir John Hicks (Chicago: Aldine Publishing Company). 